\title{
Analysis on Characteristics of Corn Farmers on Selecting Seeds Under the Seed Subsidy in China: A Case Study in Liaoning and Hebei Provinces, China
}

\author{
${ }^{1}$ Ning-Ning Sun, ${ }^{2}$ Shoichi Ito, ${ }^{1}$ Qianhui Gao, \\ ${ }^{1}$ Zhengwei Cao, ${ }^{1}$ Shuqin Yan and ${ }^{3}$ Mengqiong Zhao \\ ${ }^{1}$ Graduate School of Bio-Resources and Bio-Environmental Sciences, Kyushu University, Fukuoka, Japan \\ ${ }^{2}$ Department of the Agricultural and Resource Economics, Faculty of Agriculture, Kyushu University, Fukuoka, Japan \\ ${ }^{3}$ Undergraduate School of Art Design, Huanghuai University, Zhumadian, China
}

\begin{abstract}
The Seed Subsidy (SS) is the direct subsidy to encourage farmers cultivate with high quality seeds, which was introduced to nationwide farmers by Chinese government since 2004 . China is the second biggest corn producer in the world and the government has provided SS for the corn producers since 2004. As the government allocated an increasing amount of budgets on SS during the last decades, this study attempts to investigate the effectiveness of the SS from the social and demographic aspects of grain farmers associated with their seed choices under the allocation of SS. A descriptive analysis and OLS model are adopted to analyze including the demographic factors of grain farmers as well on selecting seeds under the circumstance of receiving SS. We found that the larger the land area endowment and the higher the income from vegetable and fruits, the higher the seed quality they apply in Gaizhou. In Yangyuan, the same situation for the land area endowment but a contrary situation for off-farm income, the more off-farm income, the lower the seed quality they apply. What's more interesting is the estimated coefficients of the awareness of the SS were statistically insignificant in both regions. In order to stimulate the use of high quality seeds, the government should set another policy system in a different way.
\end{abstract}

Keywords: Seed Subsidy, Quality Seeds, Land Area, Awareness, Off-Farm Income

\section{INTRODUCTION}

Chinese government introduced the Seed Subsidy (SS) nationwide in 2004 for a purpose to develop high-quality seeds promotion, to increase grain production with better quality and to enhance competitiveness. It was a part of China's Grain Direct Subsidy (GDS) package, which includes Grain Subsidy (GS), Seed Subsidy (SS), machinery subsidy (MS) and General Subsidy (GLS). Although the plant breeders in China have developed quite high quality varieties of grains, application of high quality seeds was not widely spread especially in the countryside. Hence, promotion of the high quality seeds among all the grain farmers turned out to be the main target for increasing yields of grains (Chen and Ding, 2011). And the SS is supposed to be a subsidy to encourage farmers to purchase improved seeds. SS was launched as a pilot program in 2002 in Heilongjiang, Liaoning, Jilin and Inner Mongolia to stimulate soybean farmers to adopt high oil content seeds. In 2004, it was introduced to 13 major grain producing provinces (Provinces include Heilongjiang, Jilin, Liaoning, Hebei, Henan, Shandong, Jiangsu, Anhui, Hunan, Hubei, Sichuan, Jiangxi and Inner Mongolia Autonomous Region) offering for soybean, wheat, corn and paddy in various regions. SS has also covered cotton and rape seeds since 2007 (Table 1).

Corresponding Author: Ning-Ning Sun, Graduate School of Bio-Resources and Bio-Environmental Sciences, Kyushu University, Fukuoka, Japan 
Table 1. Evolution of Seed Subsidies (SS)

\begin{tabular}{|c|c|c|c|c|c|c|c|c|c|c|}
\hline & & \multicolumn{2}{|c|}{ Pilot program } & \multicolumn{7}{|c|}{ Nationwide program } \\
\hline & & 2002 & 2003 & 2004 & 2005 & 2006 & 2007 & 2008 & 2009 & 2010 \\
\hline Total amount & (billion yuan) & 0.10 & 0.30 & 2.85 & 3.87 & 4.15 & 6.66 & 12.34 & 19.86 & 20.40 \\
\hline \multirow[t]{8}{*}{$\mathrm{SS}$ (yuan/mu) } & Soybean & 10.00 & 10.00 & 10.00 & 10.00 & 10.00 & 10.00 & 10.00 & 10.00 & 10.00 \\
\hline & Wheat & & 10.00 & 10.00 & 10.00 & 10.00 & 10.00 & 10.00 & 10.00 & 10.00 \\
\hline & Corn & & 10.00 & 10.00 & 10.00 & 10.00 & 10.00 & 10.00 & 10.00 & 10.00 \\
\hline & Early rice & & & 10.00 & 10.00 & 10.00 & 10.00 & 10.00 & 10.00 & 10.00 \\
\hline & Middle rice & & & 15.00 & 15.00 & 15.00 & 15.00 & 15.00 & 15.00 & 15.00 \\
\hline & Late rice & & & 7.00 & 7.00 & 7.00 & 7.00 & 15.00 & 15.00 & 15.00 \\
\hline & Cotton & & & & & & 15.00 & 15.00 & 15.00 & 15.00 \\
\hline & Rape seeds & & & & & & 10.00 & 10.00 & 10.00 & 10.00 \\
\hline
\end{tabular}

Sources: 1. MOA, 2003-2011a; 2. MOA, 2003-2011b; 3. MOA, 2010.

In most of the subsidized regions, SS was distributed to farmers directly by crediting each household's special bank account, so called "One-Card." In some of the subsidized provinces seed supplying companies were paid, expecting that they would pass on the subsidies to the farmers who were to buy the seeds at the companies. And these companies were invited for bids by the provincial governments and organized and unified farmers were to purchase seeds (MOA, 2009).

Corn is one of the important crops in the world, there are 175 million ha harvested corn area in the world in 2012 (Ito, 2012). China is the second biggest corn producer in the world, next to the U.S., with about 34 million ha in 2012, and the government has provided SS for the corn producers since 2004. As the government allocated an increasing amount of budgets on SS during the last decades, this study attempts to investigate the effectiveness of the SS from the social and demographic aspects of grain farmers associated with their seed choices under the allocation of SS.

Previous studies on this Chinese SS policy mainly focused on two categories. The first category is explaining and generally evaluating the policy. Gale et al. (2005) utilizing the general production and average subsidy determined that the SS may encourage planting of certain crop varieties, but the effect on yield is uncertain. The second category is carrying out an analysis on policy practice and effects. Zhang et al. (2011) employed Logistic model to estimate farmers' satisfaction degree with SS and concluded that education level and land area had a positive relationship with satisfaction of farmers toward SS. Chen and Ding (2011), based on rice crops using the Game theory and Cobb-Douglas model, argued that SS was effective in increasing crop quality and production.

Previous studies analyzed mostly the effects of SS on general grain production and quality, or the farmers' attitudes toward SS. However, there was no study trying to investigate the actual behavior of selecting seeds by the farmers directly influenced by the allocation of SS, nor to estimate any influence of their awareness of SS. As shown below, there are many farmers who are not aware of the existence of SS. Therefore, it is important to study the relationship between characteristics of farmers and their seed choices directly with the SS. Based on field survey, this study attempted to analyze including the demographic factors of grain farmers as well on selecting seeds under the circumstance of receiving SS.

\section{MATERIALS AND METHODS}

Our field survey in the corn producing area in China was conducted in 2009. Two areas such as Gaizhou city in Liaoning province and Yangyuan County in Hebei province were chosen as survey areas where SS covered corn production. As shown in Table 2, the two areas studied are quite different in their economic and infrastructure conditions. The pupulation of Gaizhou city is much larger with a greater share of urban population than that of Yangyuan County. Gaizhou city hosts foreign direct investment while Yangyuan County does not. Finally, transportation facilities are more developed in Gaizhou than the latter. Gaizhou city owns a railway station within the region, while Yangyuan County does not; while Gaizhou city has three available ports in adjacent areas, there are no ports in Yanyuan County. Reflecting these, off-farm employment is more available in the former while agricultural land is abundant in Yangyuan. In our survey, it was found that only ten percent of respondents own more than four $\mathrm{mu}(1 \mathrm{mu}$ is equivalent to 0.06 ha) in Gaizhou city, while $74 \%$ of farmers in Yangyuan county do the same. 
Table 2. Socioeconomic data for the two studied areas

\begin{tabular}{llllll}
\hline Region & $\begin{array}{l}\text { Urban population } \\
\text { (million) }\end{array}$ & $\begin{array}{l}\text { Rural population } \\
\text { (million) }\end{array}$ & $\begin{array}{l}\text { Hosting foreign } \\
\text { investment }\end{array}$ & $\begin{array}{l}\text { Railway stations } \\
\text { within a region }\end{array}$ & $\begin{array}{l}\text { Number of ports } \\
\text { in adjacent areas }\end{array}$ \\
\hline Gaizhou & 0.27 & 0.46 & Yes & 1 & 3 \\
Yangyuan & 0.07 & 0.20 & No & 0 & 0 \\
\hline
\end{tabular}

Note: Data constructed by 2009 base

Table 3. Interviewees' average annual income and its sources (unit: Chinese Yuan)

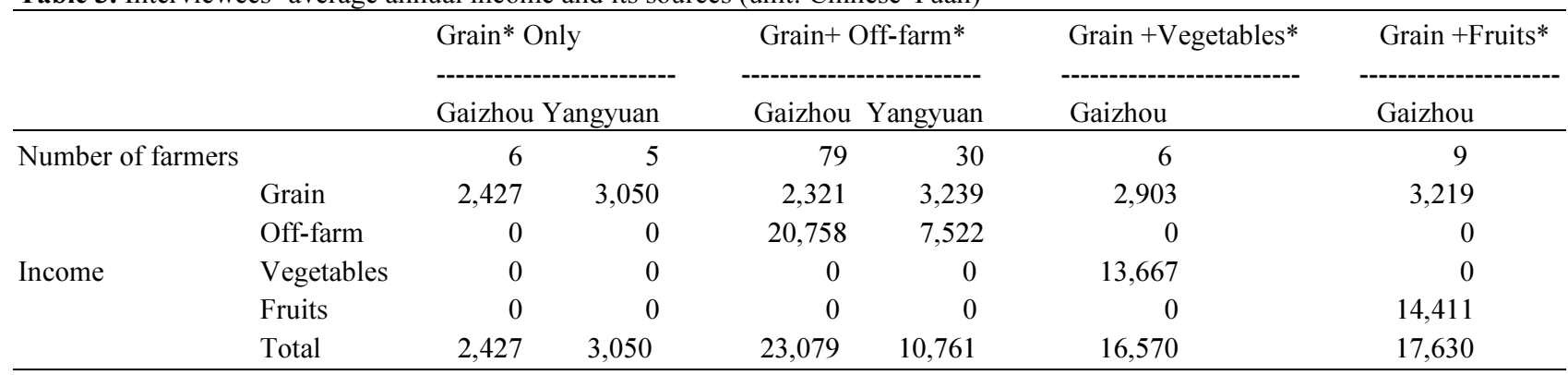

Note: * Grain, Grain + Vegetables, Grain + Fruits, Grain + Off-farm respectively denote the income sources

In the survey, we visited farmers door-to-door in several communities of Gaizhou city and Yangyuan County. Among 167 questionnaires collected, there were 135 valid responses in both areas. All of interviewed farmers had already received GDS, which includes SS. Therefore, in this survey, we focused on the impacts of their demographic and social economic factors, such as interviewees' education, farming areas and agricultural and off-farm incomes, on their corn seeds selection.

In order to further investigate the situation above, we conducted a statistical regression analysis with an equation for each area as follows:

$$
\begin{aligned}
& \sum_{j=1}^{2} \text { QS }_{i_{j}}=\alpha_{0}+\alpha_{1} \text { land }_{i}+\alpha_{2} \text { off }_{i}+ \\
& \alpha_{3} \text { aw }_{i}+\alpha_{4} \text { age }_{i}+\alpha_{5} \text { edu }_{i}+\operatorname{rd}_{i} \alpha_{6} \text { vegfru }_{i}
\end{aligned}
$$

Where:

$\mathrm{QS}_{\mathrm{i}}=$ Quality of farmer i-th corn seeds, rated by their qualities: GL and YL $=1 ; \mathrm{GM}$ and $\mathrm{YM}$ $=2 ; \mathrm{GH}$ and $\mathrm{YH}=3$

$\operatorname{land}_{\mathrm{i}}=$ Farmer i-th corn land area (unit: $\mathrm{mu}$ )

off $_{\mathrm{i}}=$ Famer $\mathrm{i}$-th annual off-farm income (unit: 10 thousand yuan/year)

$\mathrm{aw}_{\mathrm{i}}=$ Dummy variable, 1 if the farmer was aware of SS and 0 otherwise

age $_{\mathrm{i}}=$ Farmer i-th age (unit: year)

$\mathrm{edu}_{\mathrm{i}}=$ Farmer i-th educated years (unit: year)

$\mathrm{rd}_{\mathrm{i}}=$ Regional dummy variable, 1 if the farmer lives in Gaizhou and zero otherwise vegfru $_{i}=$ Farmer $\mathrm{i}$-th income from vegetables or fruits (unit: 10 thousand yuan/year)

$\mathrm{i}_{1}=1,2,3, \ldots, 100$, representing individual farmers in Gaizhou

$\dot{i}_{2}=1,2,3, \ldots, 35$, representing individual farmers in Yangyuan

\section{RESULTS}

\subsection{Results from the Field Survey}

Table 3 shows the average annual income and its sources for different types of farmers in the two regions. Interviewed farmers are classified into four categories according to their income sources: (i) grain production, (ii) grain and vegetable production, (iii) grain and fruits production and (iv) grain production and off-farm job. Farmers in these two regions hold remarkably different economic status. There were 6 out of 100 and 5 out of 35 farmers in Gaizhou and Yangyuan, respectively, getting income only from farming activities and with a comparatively lower annual income. As already stated in Table 2, farmers in Gaizhou earned more income with an easier access to off-farm jobs than the farmers in Yangyuan. Farmers' average off-farm income in Gaizhou was 20,758 yuan, more than twice the amount of Yangyuan (7,522 yuan). Besides that Gaizhou respondents also had income from vegetables or fruits, which made farmers in Gaizhou richer than those in Yangyuan. 
Table 4. Situation of applied corn seeds in Gaizhou and Yangyuan (2009)

\begin{tabular}{|c|c|c|c|c|}
\hline & & Price (yuan/kg) & Yield (kg/mu) & $\begin{array}{l}\text { Share of households } \\
\text { adopted it (\%) }\end{array}$ \\
\hline \multirow{3}{*}{ Gaizhou } & Danyu No.39 & 10 & 550 & 16 \\
\hline & Chengtian No.1 & 12 & 650 & 29 \\
\hline & Shenyu No. 28 & 14 & 750 & 55 \\
\hline \multirow[t]{3}{*}{ Yangyuan } & Yongyu No.2 & 11 & 560 & 14 \\
\hline & Zhangyu No.1059 & 12 & 650 & 66 \\
\hline & Chunyu No.2 & 14 & 740 & 20 \\
\hline
\end{tabular}

Sources: Our field survey with farmers and seeds companies

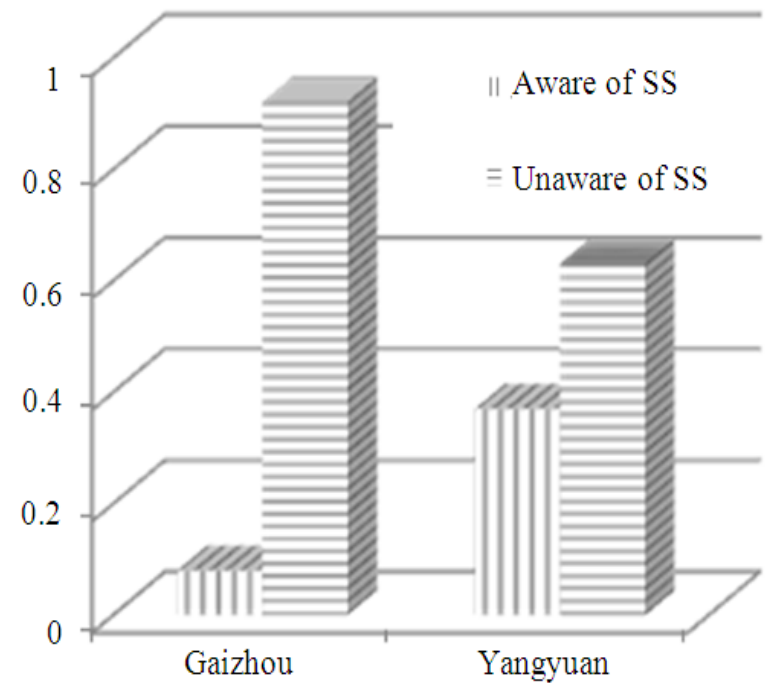

Fig. 1. Interviewees' awareness of SS

During our field survey, one unexpected situation was discovered. Because the SS is handed down the same way as the GS, which had much bigger popularity among farmers, an absence of enough and proper publicity of SS led to farmers being confused about the categories. We found that most of the interviewed farm households believed that all the money credited to their special One-Card was from the GS only. Although SS was allocated to interviewees along with the other subsidies, only a small proportion of them acknowledged the existence of it. Figure 1 shows all of these interviewees' recognition of SS and compares the differences between the two regions. Only $8 \%$ and $37 \%$ of interviewees in Gaizhou and Yangyuan, respectively, understood that they received SS in one way or the other. As long as the subsidy was credited to their individual One-Cards before spring cultivation every year, farmers are just happy to see the increasing amount of money saved in their bank account. Meanwhile, it also demonstrates that although government has an objective of SS, there is no specific restriction on the way of spending the deposited SS money. A $100 \%$ of autonomy may have some weakness in stimulating use of high quality seeds to increase production and grain quality.

There were three kinds of corn seeds cultivated in 2009 in each of the area (Table 4). Seeds choices of farmers in each area were focusing on the three brands separately. The price and yield of each variety of the seeds were almost the same in both areas. However, it was apparent that more than half of interviewees adopted the high quality seed in Gaizhou, while only $20 \%$ of interviewees did so in Yangyuan, indicating that more than $60 \%$ of interviewees applied the medium quality of seeds in Yangyuan. This just showed that farmers in different areas held different preferences in selecting corn seeds.

\subsection{Results from the Statistical Analysis}

This study attempted to analyze the influencing factors of seed choices under SS in China. Analysis above revealed that the respondents from two regions were holding different characteristics of factors that influenced their seed choices. Therefore, we operated the OLS separately. Here, the OLS regression analysis results of characeristics influencing corn seeds quality farmers cultivated is presnted in Table 5 and 6 for Gaizhou and Yangyuan, respectively.

Analysis of the survey data revealed that two out of six variables included in the model such as land area endowment and VF income are significant (at 5 and $10 \%$ ) in explaining the variation in seed choices in Gaizhou area (Table 5). The estimated coefficients of off-farm income, awareness of SS, age and education level are insignificant. In Yangyuan area, two estimated coefficients such as land endownment and off-farm income are significant at 10 and $5 \%$, respectively, in explaining the variation in seed choices (Table 6). These variables are land endowment and off-farm income and the coefficients of the other three variables such as awareness of SS, age and education level are insignificant. 
Table 5. Impacts of factors that influencing seed selecting choices in Gaizhou

\begin{tabular}{lcccr}
\hline Variable & Coefficient & std. Error & t-value & p-value \\
\hline (Constant) & $1.163^{*}$ & 0.686 & 1.696 & 0.093 \\
Land & $0.181^{* *}$ & 0.076 & 2.388 & 0.019 \\
Off-farm income & 0.061 & 0.059 & 1.037 & 0.302 \\
Awareness of SS & -0.427 & 0.257 & -1.256 & 0.119 \\
Age & 0.13 & 0.082 & 1.588 & 0.116 \\
Education level & 0.0 & 0.052 & -0.007 & 0.994 \\
Vegetable and fruits income & $0.339^{* *}$ & 0.147 & 2.303 & 0.023 \\
\hline
\end{tabular}

Dependent Variable: quality of seeds; $\mathrm{R}^{2}=0.258 ; \mathrm{n}=100 ; \mathrm{D} . \mathrm{W} .=1.073$,

Note: $* * * * *$ and $*$ indicate 1,5 and $10 \%$ significance levels, respectively

Table 6. Impacts of factors that influencing seeds selecting choices in Yangyuan

\begin{tabular}{lcccr}
\hline Variable & Coefficient & std. Error & t-value & $\mathrm{p}$-value \\
\hline (Constant) & $2.087^{* *}$ & 0.987 & 2.115 & 0.043 \\
Land & $0.090^{*}$ & 0.053 & 1.677 & 0.082 \\
Off-farm income & $-0.731^{* *}$ & 0.303 & -2.409 & 0.023 \\
Awareness of SS & 0.018 & 0.212 & 0.085 & 0.933 \\
Age & 0.038 & 0.112 & 0.340 & 0.736 \\
Education level & 0.029 & 0.069 & -0.415 & 0.681 \\
\hline
\end{tabular}

Dependent Variable: quality of seeds; $\mathrm{R}^{2}=0.360 ; \mathrm{n}=35 ; \mathrm{D} . \mathrm{W} .=2.312$

Note: $* * *, * *$ and $*$ indicate 1,5 and $10 \%$ significance levels, respectively

Corn land area endowment had positive coefficient with significance at 5\% level in Gazihou and $10 \%$ level in Yangyuan. This indicates that the larger the land area they have, the higher quality of corn seeds they choose. The owners with less size of land for corn may be experiencing a hard time to adopt the higher quality of corn seeds. In terms of off-farm income, it was significant at 5\% level and having negative impact on the high quality seeds adoption in Yangyuan, indicating that the higher the off-farm income level, the less application of high quality seeds. In Gaizhou, the VF income had a positive coefficient with significant at $5 \%$ level. It implies that those farmers with VF income, they would become the first high quality corn seeds applicants.

\section{DISCUSSION}

In this research, it was found that the larger the land area endowment, the higher the seed quality they apply and that the higher the income from vegetables and fruits, the higher the seed quality in Gaizhou. In Yangyuan, on the other hand, it was found the same situation for the land area endowment but a different situation for income levels, namely, the more off-farm income, the lower the seed quality they apply.

Those situations found with the statistically significant coefficients as described above indicate that the farmers in both regions tend to increase their production by utilizing the higher quality of seeds as they have more farmland. Regarding the income from vegetable and fruits in Gaizhou, their enormous amount of incomes, which are even larger than that from grain production per se, may have allowed them to afford to buy the more expensive higher quality seeds.

In Yangyuan, however, the off-farm incomes may be negatively influencing for purchasing higher quality of seeds. In this region, although the off-farm income is larger than grain income, the size of the off-farm income is not as large as what they earn from vegetables and fruits in Gaizhou. Therefore, the farm households with off-farm incomes in Yangyuan may have more occupied by off-farm jobs than producing grains and not rich enough to buy high quality seeds.

More interestingly, the estimated coefficients of the awareness of the SS were statistically insignificant in both regions. This implies that despite of the public announcement to make the farmers to be aware of the subsidies and to apply high quality seeds, even those farmers who are aware of the SS do not pay attention to it at the time when they purchase their seeds. And those who are unaware of the SS are out of question. Because nobody enforces them to use the deposited money in the One-Card in a certain way, the farmers may be utilizing the money without considering purchasing the quality of seeds specifically. Some may be avoiding the expensive quality seeds and they rather focus on their off-farm jobs and some may be purchasing high quality seeds because they can afford (and/) or they desire to increase production regardless the existence of the SS. 


\section{CONCLUSION}

The empirical results in this study, therefore, strongly imply that the SS is not effectively working to improve the quality of seeds applied and to increase production. The situation, that we accidentally discovered during the survey that farmers find their lump sum deposit in their One-Card account in the bank and they almost freely spend it, may have caused those results.

Based on this study, we conclude that the SS may be just working as an income subsidy but not the seed subsidy. The SS may not be working effectively as originally designed. Therefore, if the government focuses on the aim of encouraging the use of high quality seeds, they should set another policy system in a different way.

In this study, we observed the situation in the two areas in China. However, it is expected that such situations are common all over the country. A subsidy which is working only as an income subsidy may not be working properly. In recent years the SS totals about 20 billion yuan per year in the country accounting for about $15 \%$ of total agricultural subsidies may be a waste to a certain extent mal-functioning in agricultural production increases. The Chinese agricultural policies can be better utilized by spending the same amount of subsidies if each item of the subsidies should designed and conducted more precisely. Regarding the SS, some different methods should be employed such as putting the subsidy directly to the seed shops to reduce the prices of high quality seeds under a strict direction of marketing with penalty for ill-dealing.

In fact, the results in this study are quite different from those found by Chen and Ding (2011), but rather supporting the situation found by Gale et al. (2005) studied nearly a decade ago. The government has left the SS system unchanged for a long time.

China is expected to increase domestic production as much as possible. That way instead of increases in imports, the domestic farmers can better-off their own welfare under the current high agricultural prices. The government may be trying to provide them with some income subsidies. If, however, the government changes the current subsidy system, food production in China can be increased using the same amount of total subsidies. The Chinese government may need to conduct the government funding for the domestic subsidies more efficiently and put less pressure on the rest of the world.

\section{REFERENCES}

Chen, D.P. and X. Ding, 2011. Motivation and constraints of seed-subsidy policy: An empirical study of rice. J. Nanjing Agric. Univ., 34: 137-142.

Gale, F., B. Lohmar and F.C. Tuan, 2005. China's new farm subsidies. Social Science Electronic Publishing, Inc.

Ito, S., 2012. World food statistics and graphics.

MOA, 2003-2011a. China Agricultural Development Report. 1st Edn., China Agricultural Press, Beijing, China.

MOA, 2003-2011b. China Agricultural Yearbook. 1st Edn., China Agricultural Press, Beijing, China.

MOA, 2009. Responses to No. 3707 proposal of 11th National People's Congress second session.

MOA, 2010. Publicity material regarding CPA's policy on strengthen agriculture and benefit farmers.

Zhang, D.P., Z. Guo and Y.T. Bian, 2011. Analysis of factors influencing farmers' satisfaction toward seed subsidy policy-Based on survey in Henan. J. AgroTechnical Econ. 